\title{
National Registries: The Need of the Hour
}

\author{
Surath Manimala Rao \\ Indian Journal of Critical Care Medicine (2021): 10.5005/jp-journals-10071-23839
}

The paucities of registries and statistically analyzed data, the great divide between the urban and rural health care facilities, as well as the differences between private and government setups, and along with huge population burden make it almost impossible to have data on hand in our country unlike in other developed countries.

One has to evolve a robust system in health care in order to show our data on the world map. Having a good system and monitoring them is the crux of the problem. Enormous improvements have happened in the last two decades in training and technology in the healthcare arena. This made us to showcase our doctors as one of the bests in the world which in turn lead to an increase in the medical tourism. However, more work has to be undertaken to train all the paramedical personnel to overcome issues regarding implementation and data entry.

It would take great will and enormous effort from the healthcare professionals and policymakers to evolve methodologies to capture data and analyze from every hospital in India. The societies can also come together in order to make the government to understand the need of the hour. Every hospital has a medical record section that enters the data and stores them, carefully mainly to face any medicolegal issues in the future. With digitalization, these departments can be powered to not only enter data but also analyze them for onward transfer to the central and national registries which can be persuaded to be formed with help of the health ministry. If one looks at data from Europe for the number of surgeries performed annually, it appears in a graphic format giving all the details regarding each country. Germany leads by performing 2.5 to 3 million surgeries followed by Italy, UK, and so on. Even Ireland is represented with almost 500,000 surgeries per year. ${ }^{1}$

This shows that systems are in place, and they are monitored well. When such small countries represent their data so well, I do not see any reason why we are unable to do so. If and when we develop our own database, many other countries can learn from us.

Even a great initiative taken by the lancet commission did not put our country in the primary analysis. Only 10 centers participated and the data were not correctly available. This lead to not including India in the primary analysis. ${ }^{2}$ EuSOS an international epidemiology study from Europe showed crude mortality of $4 \%$ in the postoperative period. However, it did not show anything related to either complications or length of stay. ${ }^{3}$

It has been very well established that American Society of Anesthesiologists (ASA) classification (grades 1-5), and an E is added to emergency surgery, is an excellent predictor for mortality and morbidity for many decades.

An article published in the early 1990s showed that as the ASA grade increased, morbidity and mortality rose in the postoperative period. Analysis of 2,248 patients showed that the postoperative mortality and morbidity increased from $3.9 \%$ in ASA grade 1 to
Department of Critical Care Medicine KIMS Hospital, Hyderabad, Telangana, India

Corresponding Author: Surath Manimala Rao, Department of Critical Care Medicine KIMS Hospital, Hyderabad, Telangana, India, Phone: +91 09885263990, e-mail: manimalarao@hotmail.com

How to cite this article: Rao SM. National Registries: The Need of the Hour. Indian J Crit Care Med 2021;25(5):491-492.

Source of support: Nil

Conflict of interest: None

$33.7 \%$ in grade $1 \mathrm{~V}$. No patient died in ASA grade 1 but the mortality in grade $1 \mathrm{~V}$ was to the tune of $7.2 \%{ }^{4}$

The authors in this study have taken a step toward analyzing data with a minimum number of patients. It is a great initiative and let us hope it will pave the way for national registries in various areas of surgery and other branches. I am sure it will kindle enthusiasm in the younger generation to take up the challenge in the right perspective.

According to the study in 200 patients from three centers, the authors have shown that 1 in every 3 patients can develop complications and 1 in 11 patients is likely to die of complications. This of course is higher than the statistics from other economically backward countries which showed a complication rate of 1 in 6 and out of which 1 in 35 dies. $^{5}$

The authors could analyze around 200 patients, which of course is not an adequate number for any epidemiological cohort. The higher complications could be attributable to high ASA grading and complex head and neck as well as cancer surgeries. The authors noted the maximum number of complications are due to infections of various categories. This is one area one can look into, to improve the infection control program and the sanitization programs as well as educating all healthcare workers with statistics in order to reduce the burden of infection in the perioperative period. Regarding the hemoglobin percentage and the complications associated with it, the authors just mentioned in a cursory manner that complications were high in patients with higher hemoglobin levels. One has to look deeper into the type of complications and the statistical significance. One cannot comment on the paucity of available data. It has been studied in patients undergoing surgery in Jehova witnesses noted that any hemoglobin level above $7 \mathrm{gm} \%$ did not show mortality. ${ }^{6}$

The interesting part is that the study has opened our eyes to the paucity of proper registries and analyzed data in spite of doing large volumes of good work. Because of this reason, we are unable to be on the world map. By having these data, we can have our own

(0) Jaypee Brothers Medical Publishers. 2021 Open Access This article is distributed under the terms of the Creative Commons Attribution 4.0 International License (https://creativecommons.org/licenses/by-nc/4.0/), which permits unrestricted use, distribution, and non-commercial reproduction in any medium, provided you give appropriate credit to the original author(s) and the source, provide a link to the Creative Commons license, and indicate if changes were made. The Creative Commons Public Domain Dedication waiver (http://creativecommons.org/publicdomain/zero/1.0/) applies to the data made available in this article, unless otherwise stated. 
benchmarks setup in spite of the varied nature of difficulties one faces, namely, population, economy, and differences in healthcare delivery. The government has come up with good policies and protocols during this pandemic time and realized the importance of health and even increased the budget. It is, therefore, high time that we leave the negative attitude, lack of interest, and indifference and develop a good partnership with policymakers and implement the programs in such a way that data entry should be done by every hospital. Steps to be taken to make the medical records department a robust one. The government should not give license unless all data are completed annually. Let us hope people come together to implement important programs which will benefit all and make us introspect to improve the system and form solid guidelines from our own analyzed data. ${ }^{7}$

\section{OrCID}

Surath Manimala Rao 우 https://orcid.org/0000-0001-7252-6165

\section{References}

1. Gateway.Euro.Who.int/en indicators/hfa 539-6031total number of in patient surgical procedures per year.
2. Alkire BC, Raykar NP, ShrimeMG, Weiser TG, Bickler SW, Rose $J A$, et al. Global access to surgical care: a modelling study. Lancet Glob Health 2015;3(6):e316-e323. DOI: 10.1016/S2214109X(15)70115-4.

3. Pearse RM, Moreno RP, Bauer P, Pelosi P, Metnitz P, Spies C, et al. Mortality after surgry in Europe; a seven, day cohort study. Lancet 2012;380(9847):1059-1065. DOI: 10.1016/S01406736(12)61148-9.

4. Menke $\mathrm{H}$, Klein $\mathrm{A}$, John KD, Junginger T. Predictive value of ASA classification for assessment of post operative risk. Int Surg 1993;78(3):266-270. PMID: 8276556

5. Global patient outcomes after elective surgery: prospective cohort study in 27 low middle, and high income countries. $\mathrm{Br} J$ Anaesth 2016;117(5):601-609. DOI: 10.1093/bja/aew316.

6. Carson JL, Noveck H, Berlin JA, Gould SA. Mortality and morbidity in patients with very low postoperative $\mathrm{Hb}$ levels who decline transfusion. Transfusion 2002;42(7):812-818. DOI: 10.1046/j.15372995.2002.00123.x.

7. Vandana A, Radhakrishnan M, Bhagyesh AS,Rane PP, Kulkarni AP, Divatia JV, et al. Postoperative Outcomes of Patients Undergoing Elective Surgery in India. Indian J Crit Care Med 2021;25(5):528-534. 